\title{
correspondence
}

\section{Biochemical nomenclature}

SIR,-Every biochemist knows the frustration of being told to use a new name for a substance when he was perfectly happy with an old one. It can, however, be just as frustrating when different groups of workers use different nomenclature systems. Widely agreed recommendations may, at the very least, prevent a name from implying an incorrect structure; they may even indicate correct ones.

Slavish adherence to fully systematic nomenclature gives unusably long names; at the other extreme laboratory jargon is understood only by the initiated. There is therefore a need for specialised nomenclatures in many fields to compromise between the needs of the workers in the field and more general readers.

A difficulty in the past has been that names may be established before it is realised that they are misleading or ambiguous to those in related fields. A glaring example of this is 'diphosphate'. This was long used to mean two phosphate groups, and also, as in ADP, a single diphosphate group. The latter usage has been approved, and two separate groups are now distinguished by being called 'biphosphate' [strictly bis(phosphate)] as in fructose 1,6-biphosphate.

Much of the difficuity can be avoided if recommendations for a self-consistent nomenclature are agreed at the very beginning of the study of a new class of compounds. This is the thought behind general principles for naming natural organic compounds, preparcd by the Commission on Nomenclature of Organic Chemistry of the International Union of Pure and Applied Chemistry (IUPAC) and published as : Nomenclature of Organic

Chemistry, Section F, IUPAC Information Bulletin, Appendix 53, 1976 (Eur. J. Biochem. 86, 1-8; 1978).

The basic idea of Section $F$ is to have a set of stem names for each group of natural products to which the general principles of organic nomenclature will apply. Thus, unsaturation and the presence, type and number of functional groups will be indicated by prefixes and suffixes according to the standard methods of Nomenclature of Organic Chemistry, Section A-D, stereochemistry according to Section $E$ and isotopic substitution according to Section H. Modifications of a skeleton will be shown by methods first introduced in the Steroid Rules, and now set out generally in Section F.

Although Section $F$ is designed to guide individuals so that they can themselves propose a clear and simple system of nomenclature for a new class of compounds, there remain great advantage in bringing together many workers in a field to agree on how its general principles should be applied. The Joint Commission on Biochemical Nomenclature (JCBN), joint between IUPAC and IUB (International Union of Biochemistry) set up in 1977, has, as one of its main tasks, the application of these principles to appropriate groups of natural products. In this it works closely with the
Nomenclature Committee of IUB (NC-IUB).

In some areas recommendations for nomenclature have already been made. In others JCBN will be inviting specialists who are active in the biochemistry and chemistry of particular groups of compounds to form working parties to make such recommendations.

We hope that our colleagues will accept invitations to serve on such working parties and carry out an important task. We hope too that specialists in areas that need agreed nomenclature will offer to form working groups themselves. We would be glad to hear of suggestions for topics from any groups in such areas that already meet for discussion. We would be glad to hear of suggestions for topics that may need nomenclature agreements, even when not accompanied by an offer to serve on working parties!

\section{P. KARLSON}

Chairman, JCBN \& NC-IUB

Institut fur Physiologische Chemie,

Marburg, West Germany

\section{H. B. F. Dixon}

Secretary, JCBN \& NC-IUB,

Department of Biochemistry,

University of Cambridge, UK

We gratefully acknowledge the initiative of the late $W$. Klyne in preparing this letter.

\section{Has food production kept up?}

SiR,- -John Gribbin has referred (16 November, page 208) to FAO data indicating that in the past two decades, while population has grown at $2 \%$ per annum food production has grown by an average of $2.8 \%$ per annum.

As I have pointed out elsewhere (Proc. Nutrition Soc. 36, 121; 1977) such aggregate figures are highly misleading.

Whereas, in the developing countries, the total increase in food production was $2.8^{\circ}$ per annum in the $1960 \mathrm{~s}$, demand for food increased by $3.5 \%$ in those countries. Almost two-thirds of all developing countries showed a fall in self-sufficiency in 1970-72 as compared with 1961-63.

Even more critical is the situation in the food-deficit less developed countries, in which grain production increased by $2.5^{\circ}$ per annum in 1960-74 but only by $1.7^{\circ}$; per annum in 1967-74. Analysis by the International Food Policy Research Institute shows that even if grain production in those countries were to increase by $2.5^{\circ}$ per annum to 1985 , they would by then have a deficit of 100 million tonnes of grain per annum. The trend over the past four decades has been of an increasing surplus of grain in North America and an increasing deficit in the developing countries. The problem,

therefore, is not that of overall world food production but of where the food is produced, and of its distribution, both between and within different countries, and also whether it is used to feed animals or human beings.

TILO L. V. UlbRICHT Agricultural Research Council

London

\section{Mr Moon's philosophy}

SIR,-While I know very little about the ICUS of 1972 and 1973 and the organisation of $\mathrm{Mr}$ Haskell, it is ridiculous for Professor Nicholas Kurti (16 November, page 206) to place the ideas of $\mathrm{Mr}$ Moon on a par with those in Haskell's book "Full Circle: The Moral Force of Unified Science" where the latter postulates periodical tables for botany, zoology and sociology.

Professor Kurti seems to assume that he can simplify to the necessary degree to reach his conclusions situations which are extremely complex. The 'Give and Take' relation is a fundamental metaphysical principle and we are consciously or unconsciously dependent upon it. Mr Moon's philosophy asserts that the true unity exists in the Creator while in the creation there is only plurality even though it is ordered plurality. Mr Moon is concerned primarily with the order of life and with ordering life and he presents us with a conceptual apparatus which sets out many things to which we can relate in a gradual and ordered way.

I must explain that the ICUS meetings are not public relations ploys to further the Unification Church, nor are they frosting on Mr Moon's theological cake. $\mathrm{Mr}$ Moon founded the ICUS conferences because of his deep and sincere desire to set up a forum to further the striving of man to resolve "the most important problem of our time - the reconciliation of religion and science. The problem is not simply a matter of reconciling two academic disciplines. Rather the problem points to the need to investigate the dichotomy of facts (science) and values (religion and ethics). This separation of science and religion in the modern world has caused untold harm and serious damage to the development of humanity."

But while Professor Kurti himself says that the ICUS conferences should be judged by the contents of the published conference proceedings and not by selected remarks and others, his ideas about the teachings of Mr Moon's movement indeed echo the popular press. It would have been better for all concerned if Professor Kurti had consulted the official publications of Mr Moon's teachings and the activities of his movement.

JANE SALTER

International Cultural Foundation, 44 Lancaster Gate, London W2

\section{Laser progress?}

SIR,-The Christmas laser display in Oxford Street, London has just given rise to the following exchange of conversation:

Scientist: "I have a laser almost as good as that in my lab."

Companion: "Yes! But is it in colour, or only black and white?"

University of London, UK.
C. B. Lucas 